\title{
MATERNITY BLUES AMONG CROATIAN MOTHERS - A SINGLE-CENTER STUDY
}

\author{
Mislav Mikuš ${ }^{1,2}$, Bernarda Škegro ${ }^{3}$, Vesna Sokol Karadjole ${ }^{1,2}$, Joško Lešin ${ }^{1,2}$, \\ Vladimir Banović $^{1,2}$, Mislav Herman ${ }^{1,2}$, Trpimir Goluža ${ }^{1,2}$, Tomislav Puževski ${ }^{1,2}$, \\ Vesna Elveđi-Gašparović ${ }^{1,2}$ \& Goran Vujić ${ }^{1,2}$ \\ ${ }^{I}$ Department of Obstetrics and Gynecology, University Hospital Center Zagreb, Zagreb, Croatia \\ ${ }^{2}$ School of Medicine, University of Zagreb, Zagreb, Croatia \\ ${ }^{3}$ Department of Rheumatology, Physical Medicine and Rehabilitation, Sestre milosrdnice University Hospital Centre, \\ Zagreb, Croatia
}

received: 21.7.2020;

revised: 21.8.2020;

accepted: 28.8 .2020

\section{SUMMARY}

Background: Maternity blues is a transient change of mood that occurs within the first few days after delivery. Some of the most common symptoms include mood swings, tearfulness, irritability, loss of appetite, fatigue. The aim of the study was to investigate the relationship between maternity blues, psychological, demographic and obstetrics risk factors.

Subjects and methods: A cross-sectional study was conducted between October 2019 and February 2020 at the University Hospital Center Zagreb, Croatia. Final analysis included 227 mothers. Participants were assessed with Stein's Maternity Blues Scale, Connor-Davidson Resilience Scale (CD-RISC), Multidimensional Scale of Perceived Support (MSPSS) and Brennan's Experiences in Close Relationship Scale, as well as demographic and obstetric data.

Results: The prevalence of maternity blues in our study was 19.9\%. Higher result on Stein's Maternity Blues Scale was associated with anxious attachment style $(r=0.425, p<0.01)$, oxytocin $(r=0.308, p<0.01)$, lower birth weight $(r=-0.242)$, lower resilience $(r=-0.252)$ and less perceived social support from family and significant other $(p<0.01)$.

Conclusions: This report presents the very first study assessing maternity blues occurence among Croatian mothers and in Croatian cultural environment. We believe that our report will address importance of employing adequate screening methods in preventing and timely recognizing maternity blues and subsequent postpartum depression in Croatian population.

Key words: maternity blues - postpartum depression - Stein scale

$* * * * *$

\section{INTRODUCTION}

Maternity blues (MB) presents mild and transient physiological phenomenon occurred within a characteristic peak between 3-5 days postpartum (Smith-Nielsen et al. 2016). It is characterized by rapid mood swings, cognitive function and sleep deprivation, loss of appetite, and decreased overall energy level (Gonidakis et al. 2007). Unrecognized, it can lead to development of postpartum depression (PPD) which negatively affects maternal morbidity and mortality rates due to increased suicidal tendency (Gonidakis et al. 2007, Bruno et al. 2017). In other words, MB should be perceived as an end-stage of potential PPD occurrence (Bruno et al. 2017). According to an increasing body of evidence, $\mathrm{MB}$ and subsequent PPD have negative impact both on early mother-child relationship and later child social and cognitive development (Smith-Nielsen et al. 2016, Bruno et al. 2017, Takács et al. 2018). Furthermore, marital relationships also suffer, resulting with mental health problems occurring in partners of women with postpartum psychiatric disorders (Zelkowitz \& Milet 2001).

Diverse psychopathological, sociodemographic and obstetric variables are considered as a risk factor for MB although broad incosistency is noted in published reports (Takács et al. 2018, Zanardo et al. 2019, Faisal-
Cury et al. 2008). According to the recent prospective observational study, educational level, social support and mode of delivery play an integral part of $\mathrm{MB}$ development (Gerli et al. 2019). In regards to MB, the prevalence ranges from $14-76 \%$ in different countries and differs according to the population tested, screening tool and terminology used (Rezaie-Keikhaie et al. 2020). There is general consensus about greater prevalence in Western Europe and North America (Gonidakis et al. 2007). However, a recent meta-analysis conducted to investigate the prevalence of MB have shown greater pooled prevalence in low-income countries compared to higher ones (Rezaie-Keikhaie et al. 2020).

Regarding Croatian population, there are no studies assessing prevalence rate and risk and protective factors for MB development. Thus, the objectives of this study were to estimate the prevalence, and psychopathological, demographic and obstetric factors associated with $\mathrm{MB}$ in tertiary referral center in Croatia.

\section{SUBJECTS AND METHODS}

\section{Study design}

A cross-sectional study was conducted between October 2019 and February 2020 in the Department of 
Obstetrics and Gynecology, University Hospital Center Zagreb, Croatia following Institutional Review Board approval. The majority of enrolled women were admitted to the Department on the day of delivery. All enrolled participants gave written informed consent before their inclusion. To be eligible for participation, subjects are required to fulfill the following conditions: 1) females 18 years or older; 2) spontaneous vaginal birth of a singleton, full-term healthy infant (Apgar scores 9 and 10);3) uncomplicated pregnancy and delivery course; 4) adequate knowledge of Croatian language; 5) absence of history of depressive, psychotic, organic brain or eating disorders; 6) absence of cognitive impairement or intellectual disability; 7) absence of history of psychoactive substances, drugs and alcohol abuse. 250 consecutive women were enrolled in the study. Final analysis included 227 puerperal women (13 questionnaires data missing and 10 women refused to participate). Demographic and clinical data concerning pregnancy, delivery and puerpartum were collected from medical records during hospitalization and doublechecked with patient at the initial visit. All participants were asked to complete several different questionnaires at postpartum day 3, which included: Stein's Maternity Blues Scale (Stein's MBS), Experiences in Close Relationship Scale, Connor-Davidson Resilience Scale (CDRISC), Multidimensional Scale of Perceived Support (MSPSS).

\section{Measurements}

- Stein's Maternity Blues Scale is a 13-item scale designed to measure maternity blues in puerperal women. Maximum score is 26 , while score 8 or more indicates a significant mood swing. The Stein's MBS measures 8 different variables including: depression, anxiety, likelihood of relaxation, tendency for crying, energy level, appetite, somatic symptoms, and evaluates last night sleeping (Stein et al. 1980).

- Experiences in Close Relationships Scale consists of 36 items and it is a test of attachment style. Attachment dimensions Avoidance and Anxiety are calculated and on the basis of those two scales people can be grouped into four different categories (Fraley et al. 2000).

- Connor-Davidson Resilience Scale is a 25-item scale, each rated on a 5-point scale (0-4), with a maximum score 100 . Higher scores indicate greater resilience (Connor \& Davidson 2003).

- Multidimensional Scale of Perceived Support is a self-report 12-item scale to evaluate perceived social support from three sources: significant other, family and friends. Each item is rated on a seven-point Likert scale, from $1=$ very strongly disagree to $7=$ very strongly agree. Higher scores indicates higher perceived social support (Zimet et al. 1988, Ekbäck et al. 2013).

\section{Statistical analysis}

All continuous variables are presented as mean \pm standard deviation (SD). Categorical data are shown as frequencies and percentages. The correlation of Stein's MBS with other study variables was given by using Pearson's correlation coefficients or Spearman's rankcorrelation coefficient. A p-value $<0.05$ was considered significant.

\section{RESULTS}

Characteristics of the participants are shown in table 1. Average age of our participants was 31 years $( \pm 5.25)$, while average BMI was 28.57. Almost half of women in our study have a master degree $(\mathrm{N}=109,48 \%)$. Birth weight was on average 3440 grams.

Table 1. Characteristics of the participants

Age $(\mathrm{N}=227)(\mathrm{M} \pm \mathrm{sd})$
BMI $(\mathrm{N}=221)(\mathrm{M} \pm \mathrm{sd})$
Education level $(\mathrm{N}=227)$
Elementary
High school
BsC
MA

Birth weight $(\mathrm{N}=223)(\mathrm{M} \pm \mathrm{sd})$

Oxytocin $(\mathrm{N}=224)$

Epidural analgesia $(\mathrm{N}=223)$

Gestational diabetes $(\mathrm{N}=223)$

Episiotomy $(\mathrm{N}=223)$

\begin{tabular}{cr}
\multicolumn{2}{c}{$30.96 \pm 5.25$} \\
$28.57 \pm 3.80$ \\
$\mathrm{n}$ & $\%$ \\
9 & 4.0 \\
90 & 39.6 \\
19 & 8.4 \\
109 & 48.0 \\
$3440 \pm 544$ \\
137 & 61.2 \\
107 & 48.0 \\
46 & 20.6 \\
40 & 17.9
\end{tabular}

As seen from table 2, 45 women (19.9\%) had significant mood swing, according to Stein scale. Average score on resilience scale was 79.45 points. Score on Brennan's scale was somewhat higher for dimension Anxiety $(M=18.10)$ than for dimension Avoidance $(\mathrm{M}=14.57)$. On MSPSS scale, subscale significant others had highest average score $(M=6.70)$.

Table 2. Subscale and total scores on questionnaires

\begin{tabular}{lc}
\hline Stein's total score $(\geq 8)$ & $\mathrm{N}=45(19.9 \%)$ \\
CD_RISC $(\mathrm{N}=223)(\mathrm{M} \pm \mathrm{sd})$ & $79.45 \pm 11.91$ \\
Brennan Anxiety $(\mathrm{N}=224)(\mathrm{M} \pm \mathrm{sd})$ & $18.10 \pm 9.31$ \\
Brennan Avoidance $(\mathrm{N}=224)(\mathrm{M} \pm \mathrm{sd})$ & $14.57 \pm 6.75$ \\
MSPSS Significant others & $6.70 \pm 0.92$ \\
MSPSS Family & $6.53 \pm 0.97$ \\
MSPSS Friends & $6.31 \pm 1.22$ \\
MSPSS total score & $6.53 \pm 0.92$ \\
\hline
\end{tabular}

Correlation analysis included demographic risk factors (age, BMI, education level), obstetrics risk factors (oxytocin, epidural analgesia, gestational diabetes, episiotomy) and questionnaires (Stein's MBS, Experiences in Close Relationship Scale, CD-RISC and MSPSS). Data in table 3 only includes those correlation coefficients between Stein's MB scale and other risk factors 
Table 3. Correlation coefficients between Stein's MB scale and risk and protective factors

\begin{tabular}{lccccccc}
\hline & Stein's MBS & Oxytocin & Birth weight & CD-RISC & Brennan Anx & MSPSS Sig other & MSPSS Family \\
\hline Stein's MBS & 1 & $0.308^{* *}$ & $-0.242^{* *}$ & $-0.252^{* *}$ & $0.425^{* *}$ & $-0.213^{* *}$ & $-0.245^{* *}$ \\
Oxytocin & & 1 & $-0.165^{*}$ & -0.109 & 0.113 & -0.076 & -0.059 \\
Birth weight & & & 1 & 0.120 & -0.101 & 0.037 & 0.106 \\
CD-RISC & & & & 1 & $-0.217^{* *}$ & $0.267^{* *}$ & $0.345^{* *}$ \\
Brennan Anxiety & & & & & 1 & $-0.282^{* *}$ & $-0.208^{* *}$ \\
MSPSS Sig other & & & & & 1 & $0.762^{* *}$ \\
MSPSS Family & & & & & & 1 \\
\hline
\end{tabular}

$* \mathrm{p}<0.05 ; \quad * * \mathrm{p}<0.01$

whose strength is $r>|0.2|$, since values less than 0.2 are considered negligible (Tredoux \& Durrheim, 2004). As seen from table 3 , highest association was found between total score on Stein's scale and attachment dimension anxiety $(\mathrm{r}=0.425, \mathrm{p}<0.01)$, suggesting that more anxious women were also more likely to experience a mood swing. Oxytocin was found to be positively correlated with total Stein score $(\mathrm{r}=0.308, \mathrm{p}<0.01)$. On the other hand, higher result on Stein's maternity blues scale was associated with lower birth weight $(\mathrm{r}=-0.242$, $\mathrm{p}<0.01)$, lower resilience $(\mathrm{r}=-0.252, \mathrm{p}<0.01)$ and less perceived social suport from family and significant other ( $r=-0.245$ and $r=-0.213$, respectively).

\section{DISCUSSION}

Nowadays, MB occurrence should be considered as a relevant public health issue in modern societies due to its potential for PPD development and subsequent increase of overall maternal morbidity and mortality rate (Gonidakis et al. 2007, Takács et al. 2018), thus, identifying various group of protective and risk factors is mandatory. This study provides a better insight of the MB in Croatian population, particularly in its relationship to detailed psychopathological, demographic and obstetric variables. Recent study in Croatia found that most common difficulty in postpartum period was MB, followed by PPD and anxiety, while family support was protective factor (Zivoder et al. 2019).

Although it has been extensively researched for years and decades, standardization of MB definition and assessment is still lacking. This is first indicated by the difference in reported prevalence, which vary between $10-80 \%$ in individual studies (O'Hara \& Mccabe, 2013). In our study, prevalence of MB was $19.9 \%$. Our low prevalence rate compared with recently pooled MB prevalence rate in other middle-income countries (RezaieKeikhaie et al. 2020) can be explained in several different ways. Firstly, same group of authors in their large meta-analysis have acknowledged a lesser prevalence with the Stein's MB scale than with the other scales used (Rezaie-Keikhaie et al. 2020). In order to give a reflection on pathophysiology, we included consecutive women with no complication-related vaginal deliveries and healthy normal infants. Moreover, our intention was to exclude short-term negative effects of cesarean delivery, such as surgical stress or potential inability for "skin-on-skin" bonding between mother and newborn shortly after delivery. In a prospective study by Gerli and associates (2019), this relation was confirmed both in the bivariate analysis and in the multivariate logistic regression model. However, every fifth uncomplicated vaginal delivery gives potential for PPD development and this indicates importance of evolving adequate screening method for MB on worldwide level. Another explanation for our low reported prevalence is diversity of cultural contexts, socioeconomic status and overall educational level between Croatian population and lower-income countries (i.e. Eastern Africa) which have reported a far greater prevalence compared to ours $(83 \%$ vs. 20\%) (Rezaie-Keikhaie et al. 2020, Harris 1981). However, our prevalence is closer to the Western countries than middle-income ones, although our study population is anomalous in terms of including only vaginal deliveries (Rezaie-Keikhaie et al. 2020). The influence of traditional family support on the lower overall MB prevalence is specifically accentuated in Japan (Watanabe et al. 2008).

In order to establish the risk factors of MB, numerous psychopathological, sociodemographic and obstetric variables have been tested. Our study has shown that higher result on Stein's Maternity Blues Scale was associated with higher levels of anxiety, oxytocin, lower birth weight, lower resilience and less perceived social support from family and significant others. This findings are in concordance with the most studies which confirmed that sociodemographic variables such as age, education and marital status are not strictly involved in MB development (Gonidakis et al. 2007, O'Hara \& Mccabe 2013, Watanabe et al. 2008, Henshaw 2003). The relationship between intrapartum exposure to synthetic oxytocin and MB occurence was subject of many recently published cohort studies and obtained results were contradictory (Takács et al. 2018, Kroll-Desrosiers et al. 2017, Gu et al. 2015). In order to enable precise comparison it is important to provide the same oxytocin administration scheme on different study populations. According to Takacs and associates (2018), such result discrepancy between studies is product of a non-uniform oxytocin administra- 
tion, resulting with negative birth experience associated with MB and later PPD. Low neonatal birth weight and congenital anomalies are reportedly associated with MB occurence which is understandable rationale from mothers' standpoint (Murata et al. 1998). Resilience means the ability to cope with difficult and stressful situations, and is considered a protective factor for the development of other diseases (Jakovljević 2019). In other words, in people with low resilience, small life stressors can cause physical or mental disorders. Since it is a measure of stress coping ability, it is inseparable from anxiety, depression and stress reactions (Connor \& Davidson 2003). In our study, women with more MB symptoms were prone to have more anxiety symptoms as well, and were more likely to have low resilience and lower perceived family support. In other words, higher levels of resilience and higher perceived support can be seen as protective factors for MB.

One of the main strengths of our study is the exclusion of women with a history of psychiatric disorders. Given the strong association of psychiatric disorders with the development of MB and PPD, it was difficult to identify other risk factors in studies who did not take that into account. On the other hand, maternal anxiety, life stress, lack of social support, lower income and lower education level are some of the risk factors for depression during pregnancy (Webb et al. 2017). Since we had cross-sectional design of the study, it is impossible to say whether depressive symptoms occurred at early stages of pregnancy or after delivery. Another limitation of MB assessment is a lack of definition in terms of adequate timing and surveillance in postpartum period. Furthermore, diagnostic criteria differs between questionnaires used. In our study, we sought to determine MB with Stein's Maternity Blues Scale, a 13-item scale designed to measure MB in postpartum period (Stein 1980). Due to logistic and financial limitations, we assessed MB only in postpartum day 3. Although it is clearly demonstrated that the MB peak occur in postpartum day 3 (Rohde et al. 1997, Taylor et al. 1994), a possible condition underestimation sounds reasonable since MB can last sometimes more than the first week after delivery (Gonidakis 2007, Henshaw 2003).

\section{CONCLUSION}

In conclusion, this report presents the very first study assessing MB occurence among Croatian mothers and in Croatian cultural environment. However, it is important to emphasize that further neuropharmacological and epigenetic studies are warranted. We believe that our report will address importance of employing adequate screening methods in preventing and timely recognizing $\mathrm{MB}$ and subsequent $\mathrm{PPD}$ in Croatian population.
Acknowledgements: None.

Conflict of interest: None to declare.

\section{Contribution of individual authors:}

Mislav Mikuš: conception of the study, data collection, first draft, manuscript writing, interpretation of the results.

Bernarda Škegro: conception of the study, first draft, manuscript writing, statistical analysis, interpretation of the results.

Vesna Sokol Karadjole: data collection, manuscript writing, interpretation.

Joško Lešin: conception of the study, manuscript drafting, supervision.

Vladimir Banović: conception of the study, first draft, editing assistance.

Mislav Herman: manuscript writing, editing assistance, supervision.

Trpimir Goluža: study design, supervision, approval of the final version.

Tomislav Puževski: study design, first draft, approval of the final version.

Vesna Elveđi-Gašparović: study design, manuscript reviewing, approval of the final version.

Goran Vujić: study design, manuscript drafting and reviewing, supervision.

\section{References}

1. Bruno A, Laganà AS, Leonardi $V$, Greco D, Merlino $M$, Vitale $S G$, et al.: Inside-out: the role of anger experience and expression in the development of postpartum mood disorders. J Matern Fetal Neonatal Med 2017; 31:3033-8

2. Connor $K \&$ Davidson J: Development of a new resilience scale: The Connor-Davidson Resilience Scale (CD-RISC). Depress anxiety 2003; 18:76-82

3. Ekbäck M, Benzein E, Lindberg $M$ \& Arestedt $K$ : The Swedish version of the multidimensional scale of perceived social support (MSPSS) - a psychometric evaluation study in women with hirsutism and nursing students. Health Qual Life Outcomes 2013; 11:168

4. Faisal-Cury A, Menezes PR, Tedesco JJA, Kahalle $S$ \& Zugaib M: Maternity "Blues": Prevalence and Risk Factors. Span J Psychol 2008; 11:593-9

5. Fraley $R C$, Waller $N G$ \& Brennan KA: An item-response theory analysis of self-report measures of adult attachment. J Pers Soc Psychol 2000; 78:350-65

6. Gerli $S$, Fraternale $F$, Lucarini E, Chiaraluce $S$, Tortorella A, Bini V, et al.: Obstetric and psychosocial risk factors associated with maternity blues. J Matern Fetal Neonatal Med 2019; 1-6

7. Gonidakis F, Rabavilas A, Varsou E, Kreatsas $G$ \& Christodoulou G: Maternity blues in Athens, Greece. J Affect Disord 2007; 99:107-15

8. Gu V, Feeley N, Gold I, Hayton B, Robins S, Mackinnon $A$, et al.: Intrapartum Synthetic Oxytocin and Its Effects on Maternal Well-Being at 2 Months Postpartum. Birth 2015; 43:28-35 
9. Harris B: 'Maternity Blues' in East African Clinic Attenders. Arch Gen Psychiatry 1981; 38:1293

10. Henshaw C: Mood disturbance in the early puerperium: a review. Arch Womens Ment Health 2003; 6

11. Henshaw C, Foreman D \& Cox J: Postnatal blues: a risk factor for postnatal depression. $J$ Psychosom Obstet Gynaecol 2004; 25:267-72

12. Jakovljević M: Komorbiditet, rezilijencija i epigenetika iz perspektive prediktivne preventivne $i$ personalizirane medicine. Pro Mente; Medicinska naklada, 2019

13. Kroll-Desrosiers AR, Nephew BC, Babb JA, GuilarteWalker Y, Simas TAM \& Deligiannidis KM: Association of peripartum synthetic oxytocin administration and depressive and anxiety disorders within the first postpartum year. Depress anxiety 2017; 34:137-46

14. Milgrom J, Gemmill AW, Bilszta JL, Hayes B, Barnett B, Brooks $J$, et al.: Antenatal risk factors for postnatal depression: a large prospective study. J Affect Disord 2008; 108:147-57

15. Murata A, Nadaoka T, Morioka Y, Oiji A \& Saito H: Prevalence and Background Factors of Maternity Blues. Gynecol Obstet Invest 1998; 46:99-104

16. O'Hara MW \& Mccabe JE: Postpartum Depression: Current Status and Future Directions. Annu Rev Clin Psychol 2013; 9:379-407

17. Rezaie-Keikhaie K, Arbabshastan ME, Rafiemanesh H, Amirshahi M, Ostadkelayeh SM \& Arbabisarjou A: Systematic Review and Meta-Analysis of the Prevalence of the Maternity Blues in the Postpartum Period. J Obstet Gynecol Neonatal Nurs 2020; 49:127-36

18. Rohde LA, Busnello E, Wolf A, Zomer A, Shansis F, Martins $S$, et al.: Maternity blues in Brazilian women. Acta Psychiat Scand 1997; 95:231-5

19. Smith-Nielsen J, Tharner A, Krogh MT \& Vaever MS: Effects of maternal postpartum depression in a wellresourced sample: Early concurrent and long-term effects on infant cognitive, language, and motor development. Scand J Psychol 2016; 57:571-83
20. Stein GS: The pattern of mental change and body weight change in first postpartum week. J Psychosom Res 1980; 24:165-71

21. Takács L, Seidlerová JM, Štěrbová Z, Čepický $P$ \& Havliček $J$ : The effects of intrapartum synthetic oxytocin on maternal postpartum mood: findings from a prospective observational study. Arch Womens Ment Health 2018; 22:485-91

22. Taylor A, Littlewood J, Adams D, Doré C\& Glover V: Serum cortisol levels are related to moods of elation and dysphoria in new mothers. Psychiatry Res 1994; 54:241-7

23. Tredoux $C \&$ Durrheim K: Numbers, Hypothesis and Conclusions: A Course in Statistics for the Social Sciences. University of Cape Town Press ( $6^{\text {th }}$ Edition): Cape Town, 2004

24. Watanabe M, Wada K, Sakata Y, Aratake Y, Kato N, Ohta $H$, et al: Maternity blues as predictor of postpartum depression: A prospective cohort study among Japanese women. J Psychosom Obstet Gynaecol 2008; 29:211-7

25. Webb CA, Rosso IM \& Rauch SL: Internet-Based Cognitive-Behavioral Therapy for Depression: Current Progress and Future Directions. Harv Rev Psychiatry 2017; 25:114-22

26. Zanardo V, Volpe F, Luca FD, Giliberti L, Giustardi A, Parotto $M$, et al: Maternity blues: a risk factor for anhedonia, anxiety, and depression components of Edinburgh Postnatal Depression Scale. J Matern Fetal Neonatal Med 2019; 1-7

27. Zelkowitz $P$ \& Milet TH: The Course of Postpartum Psychiatric Disorders in Women and Their Partners. J Nerv Ment Dis 2001; 189:575-82

28. Zimet $G$, Powell $S$, Farley $G$, Werkman $S \&$ Berkoff $K$ : Psychometric Characteristics of the Multidimensional Scale of Perceived Social Support. J Pers Assess 1990; 55:610-7

29. Zivoder I, Martic-Biocina S, Veronek J, Ursulin-Trstenjak N, Sajko M \& Paukovic M: Mental disorders/difficulties in the postpartum period. Psychiatr Danub 2019; 31(Suppl 3):338-44

\section{Correspondence:}

Bernarda Škegro,

Sestre milosrdnice University Hospital Centre, Department of Rheumatology,

Physical Medicine and Rehabilitation

Vinogradska cesta 29, 10000 Zagreb, Croatia

E-mail: barbaric.bernarda@gmail.com 